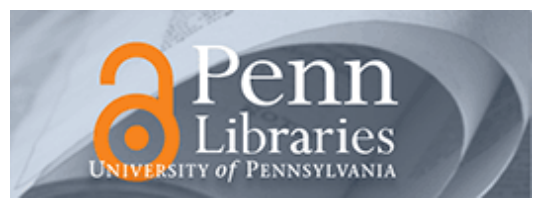

University of Pennsylvania

ScholarlyCommons

Health Care Management Papers

Wharton Faculty Research

2013

\title{
Has the Shift to Managed Care Reduced Medicaid Expenditures? \\ Evidence From State and Local-Level Mandates
}

Mark Duggan

University of Pennsylvania

Tamara Hayford

Follow this and additional works at: https://repository.upenn.edu/hcmg_papers

\section{Recommended Citation}

Duggan, M., \& Hayford, T. (2013). Has the Shift to Managed Care Reduced Medicaid Expenditures?

Evidence From State and Local-Level Mandates. Journal of Policy Analysis and Management, 32 (3),

505-535. http://dx.doi.org/10.1002/pam.21693

This paper is posted at ScholarlyCommons. https://repository.upenn.edu/hcmg_papers/88

For more information, please contact repository@pobox.upenn.edu. 


\title{
Has the Shift to Managed Care Reduced Medicaid Expenditures? Evidence From State and Local-Level Mandates
}

\begin{abstract}
From 1991 to 2009, the fraction of Medicaid recipients enrolled in HMOs and other forms of Medicaid managed care (MMC) increased from 11 percent to 71 percent. This increase was largely driven by state and local mandates that required most Medicaid recipients to enroll in an MMC plan. Theoretically, it is ambiguous whether the shift from fee-for-service into managed care would lead to an increase or a reduction in Medicaid spending. This paper investigates this effect using a data set on state and locallevel MMC mandates and detailed data from the Centers for Medicare and Medicaid Services (CMS) on state Medicaid expenditures. The findings suggest that shifting Medicaid recipients from fee-for-service into MMC did not on average reduce Medicaid spending. If anything, our results suggest that the shift to MMC increased Medicaid spending and that this effect was especially present for risk-based HMOs. However, the effects of the shift to MMC on Medicaid spending varied significantly across states as a function of the generosity of the state's baseline Medicaid provider reimbursement rates.
\end{abstract}

\section{Keywords}

Medicaid, managed care, HMO, fee-for-service 


\title{
Has the Shift to Managed Care Reduced Medicaid Expenditures? Evidence from State and Local-Level Mandates*
}

\author{
Mark Duggan** \\ The Wharton School, University of Pennsylvania, and NBER \\ mduggan@wharton.upenn.edu \\ Tamara Hayford \\ Congressional Budget Office \\ Tamara.Hayford@cbo.gov
}

January 2013

\begin{abstract}
* We are grateful to Abby Alpert, James Baumgardner, Linda Bilheimer, Jon Gruber, Judith Hellerstein, Melissa Kearney, and Rob Stewart for helpful discussions and to Samuel Hollin and Evan Nazareth for outstanding research assistance. The views expressed in this paper are solely those of the authors and should not be interpreted as those of the Congressional Budget Office, the National Bureau of Economic Research, or the University of Pennsylvania's Wharton School. All errors are our own.
\end{abstract}

** Corresponding author: The Business and Public Policy Department, The Wharton School, University of Pennsylvania, 1452 Steinberg Hall - Dietrich Hall, 3620 Locust Walk, Philadelphia, PA 19104. 


\begin{abstract}
From 1991 to 2009, the fraction of Medicaid recipients enrolled in HMOs and other forms of Medicaid managed care (MMC) increased from 11 percent to 71 percent. This increase was largely driven by state and local mandates that required most Medicaid recipients to enroll in an MMC plan. Theoretically, it is ambiguous whether the shift from fee-for-service into managed care would lead to an increase or a reduction in Medicaid spending. This paper investigates this effect using a data set on state and local level MMC mandates and detailed data from CMS on state Medicaid expenditures. The findings suggest that shifting Medicaid recipients from fee-for-service into MMC did not reduce Medicaid spending in the typical state. If anything, our results suggest that the shift to MMC increased Medicaid spending and that this effect was especially present for risk-based HMOs. However, the effects of the shift to MMC on Medicaid spending varied significantly across states as a function of the generosity of the state's baseline Medicaid provider reimbursement rates.
\end{abstract}

JEL Classification: H51, H72, I11, I18, L33

Keywords: Medicaid, managed care, HMO, fee-for-service 


\section{Introduction}

The Medicaid program currently provides health insurance to more than 60 million lowincome U.S. residents. Expenditures are jointly financed by the federal and state governments, and total program expenditures were $\$ 401$ billion in 2010 (CMS, 2010). Each state administers its own Medicaid program and has some latitude with respect to eligibility rules, which services are covered, and how generously to reimburse health care providers. States also have flexibility in how they administer the benefit, with many opting to contract with health maintenance organizations (HMOs) and other managed care organizations (MCOs) to coordinate and finance care for Medicaid recipients.

The usual motivations for Medicaid managed care (MMC) contracting are to improve quality and reduce expenditures relative to the traditional fee-for-service model. The most common type of MMC plan is the HMO, which receives a fixed amount per Medicaid recipient per month to coordinate and finance all enrollee's medical care. ${ }^{1}$ Contracting with HMOs includes the additional benefit of partially insulating the state from financial risk and thus improving budgetary predictability. The other common MMC model is primary care case management (PCCM), in which a primary care provider both monitors and approves the care received by Medicaid recipients while receiving a small management fee each month (in addition to any fee-for-service reimbursement to which they are entitled). ${ }^{2}$ By 2009, more than 71 percent of Medicaid recipients were enrolled in some form of managed care (KFF, 2010a). The corresponding share in the early 1990s was just 10 percent. The increases in MMC enrollment during this period were largely driven by state and local mandates that required certain categories of Medicaid recipients to enroll in a managed care plan.

In this paper, we use data for all fifty states and the District of Columbia to investigate the effect of MMC contracting on Medicaid expenditures. Theoretically, one might expect MMC

\footnotetext{
${ }^{1}$ In some instances specific services, such as nursing home care, may be carved out of the MMC contract.

${ }^{2}$ Some states also contract with prepaid health plans, which typically only cover limited services, such as mental health, substance abuse, and non-emergency transportation.
} 
contracting to reduce program expenditures, as HMOs would have a strong financial incentive to reduce the use of unnecessary treatments, to improve the coordination of medical care, and to keep patients healthy. Even PCCM plans could lower spending if they improved medication adherence or steered enrollees to more efficient providers. On the other hand, previous work has found that the key channel through which managed care reduces spending in the private health insurance market is by negotiating lower provider prices (Cutler et al, 2000; Dor et al, 2004; Shen and Melnick, 2006). Medicaid's provider reimbursement rates are generally much lower than those for commercial insurers, leaving little room to reduce expenditures through the price channel. Thus, even if insurers succeed in reducing the utilization of medical care, spending might increase if insurers cannot negotiate provider payment rates that are as low as the fee-for-service Medicaid program.

Previous work on the effect of MMC on Medicaid expenditures has focused on individual states, in most cases over relatively short time periods, rather than considering all states simultaneously. The results from this research provide mixed evidence, with some studies suggesting that MMC enrollment increases Medicaid spending and others finding the opposite. Of course, the results from any one state may not generalize to the nation as a whole, as each state's Medicaid program has unique features that might influence its benefits from MMC contracting. Thus it is ultimately an empirical question whether the shift of Medicaid recipients from traditional fee-forservice into managed care plans has on average reduced the strain on state budgets and also whether this effect varies across states.

To investigate this issue, we obtained data for the 1991 through 2009 time period on Medicaid enrollment, MMC enrollment, and state Medicaid spending from the U.S. Centers for Medicare and Medicaid Services (CMS). This data is available annually at the state level and includes detailed information about the type of spending (e.g. hospital, physician, managed care plan) and about the type of MMC enrollment (HMO or PCCM). During the time period that we consider, 
the fraction of Medicaid recipients enrolled in MMC plans increased from 11 percent to 71 percent, as shown in Table 1.

Our first set of empirical analyses investigates the relationship between the fraction of a state's Medicaid recipients in managed care plans and its Medicaid spending. Our specifications control for Medicaid enrollment and the demographic characteristics of Medicaid recipients. We also include state fixed effects to account for unobserved, time-invariant differences across states, year fixed effects to control for changes in Medicaid spending that are common to all states in a given year, and state-specific time trends to account for differences across states in the growth rate of Medicaid spending that are unrelated to MMC enrollment.

Our findings indicate that increases in MMC enrollment are significantly positively related with total Medicaid spending. More specifically, a 10 percentage point increase in MMC enrollment is associated with a 0.6 percent increase in Medicaid spending. This estimate is driven by the shift to Medicaid HMOs and other risk-based plans, as PCCM enrollment growth is not significantly related with Medicaid spending. Our estimates increase when we exclude those categories of Medicaid spending that would be largely unaffected by MMC. More specifically, when we exclude Medicaid DSH and long-term care spending, our estimates suggest that a 10 percentage point increase in MMC enrollment increases Medicaid spending by 1.0 percent.

One possible concern with this first set of results is that Medicaid recipients who enroll in MMC may differ in unobserved ways from those who remain in traditional fee-for-service. For example, Medicaid recipients who "opt in" to MMC may have higher or lower costs on average than their observably similar counterparts in fee-for-service. To address this concern, we next pursue an instrumental variables (IV) strategy in which we utilize data from the Urban Institute regarding state and local mandates that required Medicaid recipients to enroll in an HMO or some other form of managed care. This data set allows us to identify which counties in the U.S. had a Medicaid HMO and/or PCCM mandate in effect for each year from 1991 to 2001, and we update this data through 
2003. ${ }^{3}$ We create our instrument by using county population to construct the share of a state's residents in a county with an MMC mandate in each year.

Our analyses exploit cross-state variation in the timing and the extent of the MMC mandates. As shown in Figure 1, some states require Medicaid recipients to enroll in MMC early in our period, whereas others implement their MMC mandates much later. Similarly, while essentially all counties are covered by MMC mandates in some states, only a portion is directly affected in others. Using this MMC mandate data, we first demonstrate that our instrument is significantly positively related with MMC enrollment. More specifically, for every 10 Medicaid recipients "exposed" to an MMC mandate, there is an increase of approximately 4 in the number of MMC enrollees. The relationship is not one-for-one because some Medicaid recipients are already voluntarily enrolled and others are exempt from the mandates. ${ }^{4}$

As an additional check on our instrument, we also confirm that MMC mandates induce a significant reduction in Medicaid spending paid directly to hospitals and other health care providers and a corresponding increase in payments to Medicaid HMOs and other managed care organizations. This effect is entirely driven by HMO mandates, as these organizations finance most of the care themselves, rather than by PCCM mandates.

Using this MMC mandate variable as an instrument for a state's MMC enrollment, we next estimate the average effect of MMC enrollment on total Medicaid spending. Our key identifying assumption is that the timing of the mandates is orthogonal to other unobserved determinants of Medicaid spending. To the extent that states shift their Medicaid recipients into managed care plans after sharp changes (relative to trend) in Medicaid spending, this assumption could be violated

\footnotetext{
${ }^{3}$ We were unable to reliably update this information beyond 2003.

${ }^{4}$ Medicaid enrollees may receive exemptions from MMC mandates for reasons such as language or geographic barriers to seeing an in-network provider or having an established relationship with a non-network physician for pregnancy or complex medical needs.
} 
through regression-to-the-mean or other channels. We therefore test this assumption in a number of ways and our results generally support the validity of this assumption.

Our IV estimates for the effect of MMC on Medicaid spending are smaller in magnitude than our OLS estimates and are not statistically significant. However, the findings are broadly consistent with our OLS results in that they provide little evidence to suggest MMC lowered Medicaid spending. Additionally and consistent with our OLS results, our IV estimates suggest Medicaid HMOs increase Medicaid spending by more than did PCCM plans.

We conclude by exploring whether the effect varies with the generosity of a state's Medicaid provider reimbursement. Our results indicate that, in states where Medicaid provider reimbursement is very low (high) relative to commercial reimbursement, MMC contracting increases (decreases) Medicaid spending. Given that the effect is present for both HMO and PCCM plans, this heterogeneity could result from two distinct channels. First, if Medicaid provider rates are already much lower than commercial insurers pay, it may be difficult for an HMO to lower spending even if it reduces utilization. Second, if Medicaid provider rates are quite high, there may be a significant amount of overutilization that either an HMO or a PCCM could reduce. Both of these mechanisms may be contributing to the heterogeneity that we document, and our results suggest that Medicaid managed care is most likely to reduce spending in those states with more generous reimbursement.

Our findings regarding the effect of MMC on Medicaid spending take on additional significance when one considers that many states are currently expanding MMC to more Medicaid recipients. For example, recent survey evidence indicates that at least twenty states are planning to expand the reach of their MMC programs in the near future (KFF, 2010c). Additionally, Medicaid enrollment is projected to increase substantially during the next several years as a result of the recently enacted Patient Protection and Affordable Care Act (PPACA). 
In the pages that follow, we describe the growth in MMC during the past two decades, briefly summarize the literature on MMC, describe our data and identification strategy, and use multiple approaches to estimate the effect of MMC enrollment on Medicaid spending.

\section{The Growth in MMC Enrollment from 1991 to 2009}

In 1991 and as shown in Table 1, just 10.6 percent of Medicaid recipients were enrolled in a managed care plan. Most (7.4 percentage points) of this enrollment was in HMOs and other prepaid health plans. These plans are typically paid a fixed amount per member per month, and are responsible for choosing a network of health care providers, negotiating reimbursement rates, and managing the care of their enrollees. The key feature of the HMO payment model is that the plan is at risk for the cost of their enrollees' medical care. If enrollees' costs turn out to be higher than anticipated, the MMC plan does not receive additional reimbursement. Because of this, HMOs and other prepaid health plans have a strong financial incentive to reduce the utilization of unnecessary or low-value treatments and to include relatively low-priced hospitals, physicians, and other health care providers in their network.

A less comprehensive form of managed care used by many states during our study period is primary care case management (PCCM). Under this model, a primary care provider is paid a fixed amount per member per month to monitor and approve care for MMC enrollees (Rawlings-Sekunda et al, 2001). In contrast to the HMO model, under PCCM the physician is not at financial risk for the cost of their patients' care and does not negotiate rates with health care providers. However, PCCM providers may affect Medicaid expenditures through encouraging more efficient medical and pharmaceutical utilization or through improving care in other ways. In this baseline year, just 3.2 percent of Medicaid recipients were in PCCM.

Table 2 sheds some light on the extent to which MMC enrollment varied across states in

1991. The median state had just 3.8 percent of its Medicaid recipients enrolled in an MMC plan in 
this baseline year, and more than one-third of states had none. Thus while MMC enrollment was high in states such as Arizona, Colorado, and Utah, it was uncommon in most states. The reach of MMC enrollment grew substantially during the next twelve years. As shown in the next column of Table 2 , most states enrolled at least two-thirds of their Medicaid recipients on MMC. By 2009, most enrolled 75 percent or more of their Medicaid recipients in MMC.

The growth in MMC enrollment summarized above coincided with a substantial increase in the share of Medicaid spending accounted for by payments to MMC plans. As shown in Table 3, just 2.8 percent of Medicaid spending was paid to MMC plans in 1991. During the subsequent years, this steadily increased, reaching 9.8 percent in 1997, 16.5 percent by 2003, and 21.5 percent by 2009 . During this same period, the share of Medicaid spending going directly to hospitals, physicians, and long-term care facilities fell substantially, with these three accounting for 75.1 percent of Medicaid spending in 1991 versus just 45.0 percent in 2009.

Given that 71.2 percent of Medicaid recipients were enrolled in MMC in 2009, it is to some extent surprising that the payments to managed care plans accounted for just 21.5 percent of program spending in this year. There are three primary explanations for this. First, the majority of MMC enrollees were low-income women and children whose average spending is much lower than the elderly and disabled. ${ }^{5}$ Second, many MMC enrollees are in primary care case management, which is unlikely to produce any sharp increases in managed care payments. Third, some states "carve out" certain services from their MMC contracts so that they would continue to reimburse, for example, long-term care facilities on a fee-for-service basis.

And of course, another possible explanation is that states are able to reduce Medicaid spending by shifting recipients from FFS into MMC, and thus MMC enrollees account for a smaller share of spending than they would if they were in fee-for-service. Regardless of the explanation,

\footnotetext{
${ }^{5}$ While accounting for just one-fourth of Medicaid recipients in 2009, the elderly and disabled accounted for 66 percent of Medicaid spending in that same year (KFF, 2012). http://www.kff.org/medicaid/upload/7235-05.pdf
} 
when considering the possible effect of MMC on Medicaid expenditures, it is important to keep in mind that the plans accounted for just 21.5 percent of total program expenditures in the final year of our study period.

Another important factor to consider in the analyses below is the variation across states with respect to both the level and the growth rate of Medicaid spending per recipient during our study period. Weighting each state equally, average Medicaid spending per recipient rose from $\$ 6,217$ in 1991 to $\$ 8,084$ in 2003 (in 2010 dollars). ${ }^{6}$ This represents an annual growth rate of 2.2 percent in real Medicaid spending per recipient. Medicaid spending growth was lower over the next six years. Average Medicaid spending per recipient was $\$ 8,215$ in 2009, representing an annual growth rate of just 0.3 percent. Of course, given Medicaid expansions, changes in economic conditions, and other factors occurring during this period, the characteristics of Medicaid recipients are changing substantially over time and thus this low growth may be largely explained by these compositional changes.

There is substantial variation across states with respect to the level of spending in each year, as shown in Table 4. For example, Medicaid spending per recipient in New York was twice as high as average Medicaid spending in 1991 but fell by 0.5 percent per year during the next eighteen years. In contrast, Medicaid spending in California was 49 percent lower than average Medicaid spending in 1991 but grew by an average of 4.3 percent per year during the next eighteen years. Despite these very different growth rates, Medicaid spending per recipient in New York was still 68 percent higher than in California in 2009. These cross-state differences may partially reflect differences in the characteristics of enrollees, which services are covered, the prices paid to health care providers, and the average intensity of treatment.

\footnotetext{
6 The corresponding growth in Medicaid spending per recipient when weighting each state by its Medicaid population in each year was a rise from \$5,890 in 1991 to \$7,848 in 2003 and \$7,897 in 2009.
} 
While these cross-state differences in Medicaid spending per recipient are clearly of interest in their own right ${ }^{7}$, in our empirical analyses below, we focus on within-state variation in Medicaid spending by investigating whether it increases or declines following the shift to MMC.

\section{Previous Literature}

A large body of previous research has investigated the effect of HMOs and other managed care organizations on the quality and cost of medical care among the privately insured. The evidence on quality of care is mixed, with one influential survey article finding an approximately equal number of studies suggesting improvements as reductions (Miller and Luft, 1997). Studies focusing on cost have generally found that managed care lowers health care spending in the private sector. These savings are often achieved primarily through reductions in provider prices rather than in reductions in the utilization of medical care (Cutler et al, 2000; Dor et al, 2004). Previous evidence also suggests that managed care was more successful in reducing costs during the 1990s than in more recent years (Shen and Melnick, 2006).

Much previous work has also explored the effect of managed care in the Medicaid program, where the growth in managed care enrollment was especially rapid during the 1990s. For a number of reasons, one might expect the effect of managed care to be different for Medicaid recipients than for the privately insured. First, Medicaid's reimbursement rates for hospitals, physicians, and other health care providers are on average much less generous than the rates negotiated by private health insurers (Gruber, 2003; Garrett and Zuckerman, 2005). Thus there may be little room for these rates to fall further and induce large reductions in spending. Second, Medicaid recipients "churn" in and out of the program more frequently than their counterparts with private insurance. To the extent that managed care in the private sector achieves savings by, for example, encouraging preventive care up

\footnotetext{
${ }^{7}$ A large literature has explored the variation across geographic areas in Medicare spending per recipient (Fisher et al, 2003; Gottlieb et al, 2010). The variation shown in Table 4 for Medicaid is actually much greater than the corresponding variation for Medicare.
} 
front to reduce hospitalizations in the future, the Medicaid program may not benefit from those savings if the person is no longer enrolled. Third, the efficiency of care delivered by fee-for-service Medicaid may differ from that in the private sector. If, for example, Medicaid recipients receive more unnecessary services or care from costly sources such as emergency rooms than their counterparts in the private sector, there may be room for even greater cost savings.

A recent Robert Wood Johnson Foundation synthesis report provides a thorough overview of research on the effect of Medicaid managed care on access, quality, and expenditures (Sparer 2012). Much of the literature focuses on access and quality; this is unsurprising because managed care is a substantially different delivery system than fee for service. Managed care may improve access to physicians - particularly primary care physicians - relative to FFS Medicaid through ensuring that all MMC enrollees are connected to a primary care physician. Improved access to primary care may subsequently reduce hospitalizations and ER visits. HMOs may also improve quality through care coordination from a centralized entity. However, both PCCM and HMO programs may involve gatekeeping, which could limit access to needed specialty care, particularly if Medicaid enrollees are unable to overcome the hurdle of obtaining a referral. Likewise, the stricter network of physicians within an HMO may provide an additional barrier to receiving care.

Research on the relationship between MMC and both access and quality provide mixed results. Several studies have found that MMC - particularly HMO style programs - is associated with greater likelihood of having a usual source of care (for example, Coughlin et al 2008 and Garrett and Zuckerman 2005). However, Greene et al (2005) finds that MMC is not associated with an increase in primary care provider participation and Baker and Afendulis (2005) find that children in PCCM programs are less likely to have a usual source of care and also have more unmet needs. Similarly, Aizer et al (2007) and Kaestner et al (2005) find that MMC is not associated with improved prenatal care. 
MMC is not consistently associated with reduced preventable hospitalizations or improvements in other measures of quality, either. Bindman, et al (2005) find that MMC reduces ambulatory care-sensitive hospitalizations in California and Basu et al (2004) find slightly fewer preventable hospitalizations among MCO enrollees in a few states. Baker and Afendulis (2005) find that both PCCM and HMO programs increase outpatient use and HMOs are also associated with reduced ER visits and hospitalizations. However, Aizer et al (2007) find increases in low-birth weight and neonatal death in the same state. Howel et al (2004) and Duggan (2004) both find that managed care is not significantly associated with any changes in birth weight or in health outcomes in either direction.

Research on the effect of MMC on Medicaid spending is similarly mixed and sparse. One especially relevant study from this prior literature used data from four rounds of the Community Tracking Study (CTS) to estimate the effect of Medicaid managed care on various measures of health care utilization (Herring and Adams, 2011). The authors take this analysis one step further by exploring the effect of Medicaid managed care on expenditures, and found that HMO-style MMC did not reduce costs. However, because the CTS data does not contain information on health care spending, the authors needed to simulate it using data from another source (the Medical Expenditure Panel Survey) that allows them to estimate the average impact of each type of utilization on total spending. These estimated effects are then multiplied by the corresponding individual-specific quantities for each type of service and aggregated by the person. As the authors note, they "measure the potential effect on state program expenditures," which is certainly an important outcome variable. But to the extent that MMC plans contract with different providers, negotiate different provider reimbursement rates, or have different administrative costs than fee-for-service Medicaid, this approach may provide a misleading estimate of the effect of MMC on actual Medicaid spending.

Relatively few studies have investigated the effect of MMC enrollment on actual Medicaid expenditures. One study examined this issue in the state of California by exploiting variation across 
counties during the 1993 to 2001 period in the timing of mandates requiring certain categories of Medicaid recipients to enroll in an HMO (Duggan, 2004). The results from this study demonstrated that the policy-induced shift of Medicaid recipients into managed care resulted in a substantial increase in Medicaid spending in the state of California. In contrast, a recent survey article prepared for America's Health Insurance Plans (AHIP) found that MMC achieved cost savings in several states during the 1990s (Lewin Group, 2009). Virtually all of the studies of Medicaid spending cited in this survey article focused on just one state. ${ }^{8}$

No previous study has exploited the considerable variation across states with respect to Medicaid managed care policy to estimate the effect of MMC on Medicaid expenditures. This is in some respects surprising given the importance of the Medicaid program to both the federal budget and to individual state budgets and given the increase in MMC enrollment since the early 1990s. Indeed, there are now more than 35 million U.S. residents in some form of Medicaid managed care, and this number is likely to grow substantially in the near future as a result of additional policy changes requiring MMC enrollment and because of the PPACA-induced increase in Medicaid enrollment that will begin in $2014 .^{9}$

\section{The Relationship between MMC Enrollment and Medicaid Spending}

The typical motivation for shifting Medicaid recipients from fee-for-service into Medicaid managed care is that it will lead to improved access and quality of care for Medicaid recipients while simultaneously allowing states to reduce Medicaid spending. While several case studies of specific states suggest the possibility of cost savings (Lewin Group, 2009), no systematic analysis of a large

\footnotetext{
${ }^{8}$ The one exception to this among the articles cited in the survey is a study by Mathematica, which examines the issue for 5 states over a 3 to 6 year period during the mid-1990s. Interestingly, the authors of this study "concluded that (MMC) had little effect on state expenditures." This study, like virtually all of the other studies cited in this Lewin Group report, was not published in a peer-reviewed journal.

${ }^{9}$ CMS projects that more than one-fourth of U.S. residents will be insured by Medicaid in 2014 and that Medicaid spending will exceed expenditures by the Medicare program in each year from 2016 through 2019 (CMS, 2010).
} 
sample of states has ever been conducted. The analysis in this section aims to fill this gap by using CMS data on total annual Medicaid spending in each state from 1991 through and including 2009.

Before proceeding to the analysis, it is worth considering the relative strengths and weaknesses of using aggregate data to answer this question. Previous work on this same issue for California's Medicaid program used individual-level claims and enrollment data for a random 20 percent sample of the state's Medicaid population during the 1993 to 2001 period (Duggan, 2004). One advantage of this approach was that it allowed the author to use individual fixed effects for a large sample of program participants and thus estimate whether spending for the same individual increased or declined following a mandate-induced shift into MMC. ${ }^{10}$ However, one important disadvantage was that it excluded certain categories of Medicaid spending such as administrative costs, which are not included in claims data and might plausibly change following a shift to MMC. Similarly, this previous study ignored the possibility of general equilibrium effects - namely that shifting Medicaid recipients into MMC might affect how health care providers treated those remaining in FFS. The aggregate state data utilized in the present study includes a more comprehensive measure of Medicaid spending and would capture those general equilibrium effects. ${ }^{11}$ Turning now to our analyses of state-level Medicaid spending, our key explanatory variable is the share of Medicaid recipients in MMC plans. We also estimate several specifications in which we differentiate between HMO and PCCM enrollment. Our baseline specification is as follows:

(1) $\log \left(\operatorname{McdSpend}_{\mathrm{kt}}\right)=\alpha_{1 \mathrm{t}}+\rho_{1 \mathrm{k}}+\mu_{1} * \log \left(\operatorname{McdRecips}_{\mathrm{kt}}\right)+\beta_{1} * \mathrm{MMC}_{\mathrm{kt}}+\delta_{1} * \mathrm{X}_{\mathrm{kt}}+\mathrm{t} * \rho_{1 \mathrm{k}}+\varepsilon_{1 \mathrm{kt}}$

In this equation, the dependent variable is the log of Medicaid spending. We control for the log of the number of Medicaid recipients to account for the fact that Medicaid spending will tend to be much

\footnotetext{
${ }^{10}$ With a sample of more than one million Medicaid recipients, an additional benefit of the individual-level data was that it yielded relatively precise estimates.

${ }^{11}$ It is also worth noting that, in order to perform an analysis similar to the California one for the entire U.S., it would be necessary to obtain Medicaid claims data for all fifty states, as CMS does not currently produce a random sample for Medicaid as they do for Medicare. This no doubt also partially explains why many issues that have been researched extensively for Medicare, such as variation across geographic areas in spending and treatment patterns, have been virtually ignored for the Medicaid program.
} 
higher in states with high Medicaid enrollment like California than in low enrollment states like North Dakota. We also control for the age distribution of Medicaid recipients (fraction ages 0-14 and fraction age 65 and up), and for the fraction eligible because of blindness or a disability. Each specification that we estimate includes a full set of state fixed effects and state-specific linear time trends to control for differences in both the level and the growth rate of spending across states that are unrelated to MMC enrollment. We also include a full set of year fixed effects to control for changes in Medicaid spending that are common to all states.

In contrast to a specification that uses per-recipient Medicaid spending as the dependent variable, this specification allows spending for the marginal recipient to differ from the average recipient. If marginal recipients tend to be less expensive than the average, then the coefficient estimate on $\mu_{1}$ will be less than 1 . As we discuss below, our results are qualitatively similar if we instead use per-recipient Medicaid spending as our dependent variable.

The explanatory variable of interest is $\beta_{1}$, which captures the relationship between MMC enrollment and Medicaid spending after controlling for the variables described above. To the extent that MMC enrollment leads to lower spending, one would expect a negative estimate from this parameter. Of course, it is possible that changes in MMC enrollment are correlated with other unobserved determinants of Medicaid spending, and thus $\beta_{1}$ may not capture the average causal effect of MMC enrollment. To address this concern, in the next section we estimate a companion set of specifications using an instrumental variables strategy.

The first column of Table 5 summarizes the results from our baseline specification. Our point estimate for $\beta_{1}$ is 0.057 and this is statistically significant at the 10 percent level. This suggests that a 10 percentage point increase in MMC enrollment is associated with a 0.6 percentage point increase in Medicaid spending. This is to some extent surprising given that a primary motivation for shifting Medicaid recipients into MMC plans is often to reduce spending. Our results strongly suggest that 
the opposite is true. The estimate for $\mu_{1}$ is substantially less than 1 at 0.203 , suggesting that the marginal Medicaid recipient has lower spending than the average recipient. The significantly negative estimate on the share under the age of 15 is as expected given that children are on average much less expensive than other Medicaid recipients. The estimates for the coefficients on the share elderly and the share blind or disabled are both positive, as expected, but are not statistically significant.

In the next specification we split the \% MMC variable into the share in PCCM plans and the share in HMOs and other risk-based plans. The significantly positive point estimate for HMO plans is almost three times as large as the insignificant estimate for PCCM plans (0.073 versus 0.025$)$ and these two estimates are significantly different from one another at the 10 percent level (p-value of .065). It therefore appears that the increase in spending associated with the shift to MMC plans is driven by HMOs and other risk-based plans.

One potential concern with this first set of estimates is that it includes all categories of Medicaid spending. There are certain components of Medicaid spending that are very unlikely to be affected by MMC contracting, such as long-term care and Disproportionate Share hospital payments. Thus in the next three pairs of specifications we consider alternative measures of Medicaid spending that exclude one or both of these components. In every case, the point estimate is larger than in our baseline specification. For example when we exclude both categories of spending, the point estimate for $\beta_{1}$ on the $\%$ MMC variable increases from 0.057 to 0.101 , with this latter estimate significant at the five percent level. Had the estimates instead remained the same or declined, it might suggest that we were picking up the effect of other shocks to Medicaid spending that were affecting all categories. Instead, our results strongly suggest that the components of Medicaid spending most affected by MMC grow more rapidly than the unaffected components when MMC enrollment grows. 
In the final pair of specifications, we focus on the 1991 through 2003 period given this is the same time period during which we have information on MMC mandates, which serve as our instrument in the next section. In general the point estimates are almost identical to the ones in our baseline specification though because the standard errors increase somewhat they are no longer statistically significant.

Our results are very similar if we explore the relationship of the fraction in MMC with Medicaid spending per recipient. ${ }^{12}$ For example if we estimate a specification in which we use this as our dependent variable (and thus no longer control for the log of the number of Medicaid recipients) we obtain a point estimate of 373 . Given average Medicaid spending per recipient of 6253 during our study period, this is equivalent to a 6.0 percent increase, which is almost exactly the same as the implied effect from the log of Medicaid spending specification.

One final concern with this first set of specifications is that it considers all Medicaid recipients simultaneously. If one looks across Medicaid eligibility categories, it is clear that children and non-elderly adults who are eligible due to low income (as opposed to because of a disability) are much more likely to enroll in managed care. ${ }^{13}$ We therefore obtained data from an alternative source within CMS on Medicaid spending by eligibility category for the 1999 (the first year available) through 2009 period. ${ }^{14}$ Estimating an analogous specification to the one in the first column of Table 5, we obtain a point estimate of 0.047 for this group, which is very similar to the baseline point estimate of 0.057 . More importantly, our estimate for all other Medicaid recipients is slightly negative (-0.044). This provides further support for our results above as it suggests that Medicaid

\footnotetext{
${ }^{12} \mathrm{We}$ also estimated specifications in which we explored the relationship of the explanatory variables described above with the change in the log of Medicaid spending. Our results with this dependent variable were qualitatively similar, suggesting that if anything the shift to MMC increased the growth rate of Medicaid spending.

${ }^{13}$ As shown in Appendix Table 1, almost half (49.5 percent) of Medicaid spending for children and adults in 2009 went to MMC plans while the corresponding share for other Medicaid recipients was less than half that amount.

${ }^{14}$ The Medicaid spending by eligibility category was obtained from the following website: http://msis.cms.hhs.gov.
} 
spending rose differentially for the eligibility categories most affected by MMC when the share in MMC increased.

Taken together, the results in this section strongly suggest that the shift to MMC has on average increased rather than reduced Medicaid spending. In the next section we probe further on these results by instrumenting for the share in MMC using state and local MMC mandates.

\section{The Effect of State and Local Mandates on MMC Enrollment}

The OLS results described in the previous section suggest that Medicaid managed care programs - in particular, HMO and other risk-based programs-increase state Medicaid expenditures. However, certain populations make a choice to enroll in managed care, whether because of county-based policies or because of their preferences for medical care. ${ }^{15}$ These choices to enroll in managed care (or not) may introduce selection bias into our OLS results. This section outlines our strategy for using the presence of a state or local MMC mandate as an instrumental variable for Medicaid managed care enrollment. We begin by summarizing why an instrument is useful in our application.

\section{A. The Endogeneity of Voluntary MMC Enrollment}

At the individual level, Medicaid spending varies substantially across individuals as a function of observable factors such as age, basis of eligibility, and state of residence and unobservable factors such as illness severity. Isolating the effect of MMC from these other factors is difficult if individuals have the option to enroll in Medicaid managed care plans. For example, health insurers may find it optimal to target marketing to Medicaid recipients with relatively low costs, conditional on their observable characteristics, given that they are paid a fixed amount per

\footnotetext{
${ }^{15}$ Through 1996, over half of people living in counties with any type of Medicaid HMO program were only exposed to voluntary HMO programs. This share dropped rapidly beginning in the mid-1990s, but remained roughly $40 \%$ in 1997 and $25 \%$ in 1998.
} 
enrollee per month. Similarly, individuals with higher utilization may prefer to remain in traditional fee-for-service Medicaid, where they may face fewer restrictions on the quantity of care that they receive or may have long-standing relationships with certain health care providers. On the other hand, these same recipients may have more to gain from better coordination of their medical care, and thus may prefer to "opt in" to voluntary managed care plans. Thus it is theoretically ambiguous whether healthier (low-cost) Medicaid recipients would be more likely to "opt in" to a voluntary MMC program. ${ }^{16}$

Previous work on Medicaid managed care in the state of New York found that AFDC recipients who voluntarily enrolled in MMC differed on both observable and unobservable dimensions from those remaining in fee-for-service (Glied et al, 1997). For example, MMC enrollees were much more likely to be in good or excellent health than those in traditional Medicaid. The authors conclude that "selection affects estimates of utilization savings between managed care and fee-for-service" in Medicaid. More recent work for the Medicare program, which does not require managed care enrollment, also indicates that healthier recipients are significantly more likely to join managed care plans (Brown et al, 2011). To the extent that the individuals who voluntarily enroll in MMC differ from their observably similar counterparts who remain in fee-for-service, a plausibly exogenous source of variation in MMC enrollment can be used to estimate its effect on spending or other outcome variables of interest.

\section{B. State and Local MMC Mandates}

Virtually every state now requires at least some of its Medicaid recipients to enroll in managed care plans. These mandates typically vary by geography and/or by basis of Medicaid eligibility. For example beginning in the spring of 1994, individuals who qualified for Medicaid

\footnotetext{
${ }^{16}$ These same endogeneity concerns would exist at the state level as well. If, for example, a state's Medicaid recipients were becoming unobservably healthier (or sicker) over time because of changes in state outreach efforts, eligibility rules, or economic conditions, one might find a mechanical change in the share in MMC.
} 
through the Aid to Families with Dependent Children (AFDC, now Temporary Assistance to Needy Families) in California's Sacramento County were required to enroll in a Medicaid managed care plan. Elderly and disabled Medicaid recipients in Sacramento had the option to enroll but were not required to do so. Previous work used county-level MMC mandates as a plausibly exogenous source of variation to estimate the effect of MMC enrollment on Medicaid spending in the state of California (Duggan, 2004).

The current study extends this approach by using data on MMC mandates and Medicaid spending for all fifty states during the period when MMC enrollment experienced most of its growth. The last two columns of Table 1 show how MMC mandates have expanded over time. In 1991, only 5.9 percent of the U.S. population resided in a county with an MMC mandate of any kind; only 3.0 percent resided in a county with a mandate to enroll in an HMO. ${ }^{17}$ The remaining mandates either required PCCM enrollment or required enrollment in either PCCM or an HMO plan. The difference between the population residing in counties with mandates and actual MMC enrollment suggests that much of the MMC enrollment in 1991 was in voluntary programs. By 2003, over three-quarters of the U.S. population resided in a county with an MMC mandate, and two-fifths resided in a county with a mandate to enroll in an HMO. Note that the mandate survey data is only available through 2001, and could only be extended through 2003. Thus, our primary IV specifications will only cover the 1991-2003 time period.

As shown in Table 2, the vast majority of states had no MMC mandates in effect at the beginning of our study period in 1991. This changed significantly during the next twelve years, so that by 2003 all but six states required at least some of their Medicaid recipients to enroll in a managed care plan. This pattern tracks closely to the actual MMC enrollment. For example, these six states all had MMC enrollment below 15 percent in 2003, while none of the remaining 45 states

\footnotetext{
${ }^{17}$ We obtained information on state and county-level MMC mandates in each year from Urban Institute county-level surveys. These mandates are typically set at the state level, but often vary across counties (thus we refer to them as "state and local mandates"). See the Data Appendix for more details on the Urban Institute surveys.
} 
enrolled less than 28 percent of their Medicaid recipients in MMC. In 2003, we estimate that 77.9 percent of Medicaid recipients resided in a county with an MMC mandate, versus just 5.9 percent in 1991. From 1991 to 2003, the fraction of Medicaid recipients enrolled in MMC plans increased from 10.6 percent to 58.4 percent.

Actual MMC enrollment is lower than the estimated share residing in a county with an MMC mandate for at least three reasons. First, many categories of Medicaid recipients are not subject to the mandates. The aged, blind, and disabled individuals who qualify for Medicaid through the Supplemental Security Income (SSI) program are often excluded from MMC mandates. Second, there is often a lag between new Medicaid eligibility and enrollment in an MMC plan. And finally, some individuals who are subject to the mandate receive an exemption and thus remain in traditional FFS.

The following specification describes our first stage specification of the relationship between MMC mandates and MMC enrollment:

$$
\text { (2) } \mathrm{MMC}_{\mathrm{kt}}=\alpha_{1 \mathrm{t}}+\rho_{1 \mathrm{k}}+\beta_{1} * \text { Mandate }_{\mathrm{kt}}+\delta_{1} * \mathrm{X}_{\mathrm{kt}}+\mathrm{t} * \rho_{1 \mathrm{k}}+\varepsilon_{1 \mathrm{kt}}
$$

In this specification, $\mathrm{k}$ and $\mathrm{t}$ index states and years, respectively. $\mathrm{MMC}_{\mathrm{kt}}$ represents the fraction of state k's Medicaid recipients enrolled in managed care in year t, while Mandate ${ }_{\mathrm{kt}}$ equals our estimate of the fraction of state k's Medicaid recipients residing in a county with an MMC mandate. Regarding this latter variable, we do not have county-level Medicaid enrollment for most of our study period. Thus to estimate the share of a state's Medicaid recipients residing in a county with an MMC mandate, we weight each county by its share of the state population in each year. ${ }^{18}$ In this specification, we also include some controls for the characteristics of each state's Medicaid recipients, such as the fraction who are under the age of 15 and the fraction who are elderly (65 and older), in the vector $X_{k t}$. The specification also includes 13 year fixed effects $\left(\alpha_{1 t}\right)$ to control for

\footnotetext{
${ }^{18}$ Our results, which we summarize below, are very similar if we instead weight by the county's share of the state's low-income population or if we use the county population for just one specific year rather than allowing this population to change over time. See the Data Appendix for more details on our variable construction.
} 
common changes throughout the U.S. in MMC enrollment. The vector $\rho_{1 \mathrm{k}}$ represents a full set of state fixed effects, and these are also interacted with the year to construct a full set of state-specific linear time trends. Compressing the rich variation in the county-level data to 50 states plus D.C. is admittedly a limitation of this approach. However, an important benefit is that it allows us to estimate the average effect in all 50 states and the District of Columbia simultaneously rather than estimating the effect in just one state as in previous work.

The parameter of particular interest in equation (1) is $\beta_{1}$, which captures the relationship between the share of a state's Medicaid recipients residing in counties with MMC mandates and the fraction actually enrolled in MMC. The key assumption that is necessary to assign a causal interpretation to $\beta_{1}$ is that the MMC mandates are, after controlling for the characteristics of a state's Medicaid recipients, state fixed effects, and state-specific linear time trends, orthogonal to other unobserved determinants of MMC enrollment. If, for example, states tended to implement MMC mandates in counties where they expected voluntary MMC enrollment to decline, this would lead to a biased estimate of the average causal impact of the mandates.

\section{The Effect of MMC Mandates on MMC Enrollment}

Table 6 summarizes the results from several specifications similar to (1). The first (not numbered) column in this table displays the mean and standard deviation of the included explanatory variables. Over the course of the 13-year study period, just over half of the population in the average state resided in counties with some kind of MMC mandate. Interestingly, nearly half of that population was subject to an HMO policy, while the remainder was split between PCCM mandates and mixed mandates - which required enrollment in either PCCM or an HMO plan.

The remaining (numbered) columns report the results from variations on the first stage specification. The first three columns report results from specifications that include overall MMC 
enrollment share as the dependent variable and the share of state population residing in a county with an MMC mandate as the primary explanatory variable. The first specification includes state and year fixed effects only, the second specification adds demographic control variables, and the third specification adds state-specific trends. Standard errors in this table and all subsequent ones are clustered by state to account for the possibility of within-state interdependence in the residuals due to serial correlation (Bertrand et al, 2004). In each specification, $\beta_{1}$ is substantial and precisely estimated, ranging from 0.465 in the most parsimonious specification to 0.374 in the least.

The final three specifications break the primary explanatory variable into its three components: the share of the state population residing in a county with a PCCM mandate, mixed mandate, or HMO mandate. The results listed in column (4) show that each of these three mandate types were strongly predictive of overall MMC enrollment, with precisely estimated coefficients ranging from 0.329 for the share residing in a PCCM mandate county to 0.418 for the share residing in a mandatory HMO county. Columns (5)-(6) demonstrate the relationship between these explanatory variables and enrollment in PCCM and HMO plans. Not surprisingly, the share residing in a mandatory PCCM county has a strong predictive relationship with PCCM enrollment, and no relationship with HMO enrollment (coefficients are 0.373 and -0.044 , respectively). The converse is true for the share of a state population residing in a mandatory HMO county (coefficients of -0.040 for the PCCM specification and 0.458 for the HMO specification). There is a substantial and precisely estimated coefficient on the share residing in a mixed mandatory county in both columns, suggesting that mixed mandatory policies are relevant for both PCCM and HMO enrollment. Comparing the coefficient in column (5) of 0.263 to the coefficient in column (6) if 0.149 suggests that residing in a mixed mandatory county is more strongly related to PCCM enrollment than HMO enrollment. This comparison is unsurprising because Medicaid recipients in these counties are often auto-enrolled in a PCCM plan if they do not choose their own plan. 
Taken together, the results in this section demonstrate that the MMC mandates implemented by state and local governments during our study period led to significant increases in MMC enrollment. From 1991 to 2003, the fraction of Medicaid recipients with a mandate in their county increased from 5.9 percent to 77.9 percent. Multiplying the increase in this share by our estimate of the average effect of the mandates on MMC enrollment in the third specification (0.374), we estimate that the mandates induced a 26.9 percentage point increase in MMC enrollment. This represents more than half of the actual increase of 47.8 percentage points during our study period.

\section{The Effect of Mandate-Induced MMC Enrollment on Medicaid Expenditures}

As shown in Table 3, the shift from fee-for-service to managed care within the Medicaid program during our study period was associated with a significant shift in the composition of Medicaid spending. In the eighteen years from 1991 to 2009, payments to managed care organizations grew by an average of 18.1 percent per year (from $\$ 4.2$ billion to $\$ 83.4$ billion) versus just 5.5 percent annually for all other Medicaid spending. As a result, payments to HMOs and other MCOs rose from 2.8 percent of Medicaid spending in 1991 to 21.5 percent by 2009. As discussed above, this 2009 expenditure share is substantially below the corresponding share of Medicaid recipients enrolled in MMC because many of the payments for more expensive categories of recipients and types of services, as well as those for services provided under PCCM programs, are paid on a fee-for-service basis.

We begin our IV expenditure analyses by estimating the effect of mandate-induced MMC enrollment on the share of Medicaid spending paid to MMC organizations versus directly to health care providers. This sheds some light on the extent to which MMC could plausibly have affected total Medicaid spending. To do this, we use the mandate variables described above as instrumental variables for the share of a state's Medicaid recipients enrolled in MMC. The specifications 
summarized in columns (3), (4), and (6) of Table 6 represent our "first-stage" in the IV specifications below.

The key assumption of this empirical approach is that, after controlling for state fixed effects, state-specific linear time trends, and the other explanatory variables described above, the timing of the MMC mandates is unrelated to unobserved factors that would influence the composition or level of total Medicaid spending in a state. If, for example, states tend to shift their Medicaid recipients into MMC plans in response to previous or expected future increases in Medicaid spending, our estimates could be biased.

While it is not possible to rule out all possible sources of omitted variable bias, we test our key identifying assumption in a number of ways. First, we explore whether the MMC mandates are systematically related with total Medicaid enrollment. ${ }^{19}$ If state policymakers were responding to projected enrollment-induced increases in program expenditures by shifting more of their beneficiaries into MMC plans, one would expect to estimate a positive value for $\mu_{2}$ in the following specification:

$$
\text { (3) } \text { Mandate }_{\mathrm{kt}}=\alpha_{2 \mathrm{t}}+\rho_{2 \mathrm{k}}+\mu_{2} * \log (\text { Medicaid Recipients } \mathrm{kt})+\mathrm{t} * \rho_{2 \mathrm{k}}+\varepsilon_{2 \mathrm{kt}}
$$

Note that in this specification, the outcome variable is the fraction of Medicaid recipients with an MMC mandate in their county while the key explanatory variable is (the log of) the number of Medicaid recipients. Our estimate for $\mu_{2}$ from this specification is small in magnitude (0.003) and statistically insignificant (p-value of 0.988 ), thus providing little support for the hypothesis that state

\footnotetext{
${ }^{19}$ We take the log of Medicaid enrollment given the very large differences across states in Medicaid enrollment. For example in 2003, Medicaid enrollment in California was 6.27 million versus just 53.8 thousand in North Dakota. Thus in specification (2), year effects control for common proportional changes in Medicaid enrollment, while statespecific linear trends allow for a constant growth rate in enrollment. For the same reasons in our analyses of total Medicaid spending, we take the log of this variable.
} 
policymakers responded to Medicaid enrollment increases by shifting more of their recipients into managed care plans. $^{20}$

We next investigate whether the mandates are driven by past increases in Medicaid expenditures by estimating specifications of the following type:

$$
\text { (4) } \text { Mandate }_{\mathrm{kt}}=\alpha_{3 \mathrm{t}}+\rho_{3 \mathrm{k}}+\theta_{3} * \log \left(\text { Medicaid Spending } \mathrm{k}_{\mathrm{k}, \mathrm{-}}\right)+\mathrm{t} * \rho_{3 \mathrm{k}}+\varepsilon_{3 \mathrm{kt}}
$$

To the extent that state policymakers respond to increases in their Medicaid spending by shifting more of their recipients into managed care plans in the future, one would expect to obtain a positive estimate for $\theta_{3}$. However, we once again obtain a small and statistically insignificant estimate (of .028 with a p-value of 0.862 ), suggesting that the mandates are not being driven by accelerations in state Medicaid spending.

Another potential concern is that state policymakers shifted Medicaid recipients into MMC plans in response to past, current, or expected changes in economic conditions. To explore this possibility, we also estimated specifications similar to (3) and (4), in which we replaced the independent variable with one of three state-level unemployment variables: lagged, contemporaneous, and next year's unemployment rate. In all three cases, the coefficient was statistically insignificant, and the t-statistic never exceeded 0.50 . These results suggest that mandate implementation was not correlated with the business cycle. Further threats to validity may of course still exist. For example, other changes in Medicaid programs that could affect Medicaid expenditures may not be orthogonal to mandate implementation. For example, states may cut eligibility criteria (or reduce outreach) while simultaneously shifting recipients to MMC plans. Likewise, Medicaid recipients may migrate between mandate and non-mandate counties in response to mandate implementation. These changes would likely change the composition of Medicaid recipients. Our

\footnotetext{
${ }^{20}$ We also estimated specifications with the lag of this Medicaid enrollment measure, which essentially tests whether current Medicaid enrollment is related with mandates in the next year. However, our estimates from this specification are similarly small in magnitude and statistically insignificant.
} 
controls for the age and eligibility categories of Medicaid recipients in our expenditure specifications should go some way toward addressing this concern.

\section{A. The Effect of Mandate-Induced MMC Enrollment on the Composition of Medicaid Spending}

Table 7 summarizes the results from specifications that investigate the effect of the mandateinduced increases in MMC enrollment on the composition of Medicaid spending. This table provides evidence that the switch to managed care caused a shift from providers to managed care plans, validating the mandate and MMC enrollment variables. The first column summarizes the results from this specification, in which the outcome variable is the share of a state's Medicaid spending being paid to hospitals, physicians, and other health care providers:

$$
\text { (5) } \text { ProviderShare } \mathrm{kt}=\alpha_{4 \mathrm{t}}+\rho_{4 \mathrm{k}}+\beta_{4} * \mathrm{MMC}_{\mathrm{kt}}+\delta_{4} * \mathrm{X}_{\mathrm{kt}}+\mathrm{t} * \rho_{4 \mathrm{k}}+\varepsilon_{4 \mathrm{kt}}
$$

We instrument for $\mathrm{MMC}_{\mathrm{kt}}$ using the fraction with a mandate (see the first stage specification 3 from Table 6). To the extent that MMC mandates cause a shift in Medicaid spending from health care providers to managed care plans, one would expect a negative estimate for $\beta .^{21}$ Given that (1) MMC enrollees tend to have lower costs on average than their counterparts who remain in fee-for-service and (2) more than one-fourth of MMC enrollment is in primary care case management, one would expect the magnitude of this estimate to be substantially less than one. Consistent with this, the statistically significant estimate for $\beta_{4}$ displayed in column (1) is -0.125 . The second column includes the share of Medicaid recipients enrolled in an HMO as an additional explanatory variable because, unlike PCCMs, HMOs typically coordinate and finance most of the medical care for their enrollees. As might be expected, there is a strong negative relationship ( $\beta_{4}$ equal to -0.382$)$ between the share

\footnotetext{
${ }^{21}$ To the extent that shifting from FFS to MMC increased overall spending, one would see a slightly larger increase in the capitation share than if overall spending was unchanged. Suppose, for example, that a 10 dollar reduction in FFS spending (caused by a shift to MMC) was associated with a 15 dollar increase in capitation spending. In that case, the capitation share would increase somewhat more than if total spending was unchanged.
} 
of payments going directly to health care providers and Medicaid HMO enrollment. There is no corresponding relationship for PCCM enrollment, which is consistent with the predictions above.

The next two columns of Table 6 reveal that the decline in provider share is almost perfectly offset by an increase in the share of Medicaid spending going to managed care plans. The share of Medicaid spending going to other sources, such as administrative costs or Medicare premiums (for Medicaid recipients dually eligible for Medicare), is not significantly related with the mandateinduced increases in MMC enrollment, as shown in columns 5 and 6.

If one assumes that Medicaid HMOs finance all of the medical care for their enrollees (and thus there is no fee-for-service spending on their behalf), then the estimate of -0.382 suggests that HMO enrollees are much less expensive than the average Medicaid recipient. Suppose, for example, that half of the Medicaid recipients in a state are shifted into Medicaid HMOs. The statistically significant point estimates of -0.382 in column 2 and of 0.388 in column 4 suggest that approximately 20 percent of Medicaid spending would be shifted from providers to insurers. In this example, the other half of recipients remaining in fee-for-service would account for 80 percent of spending, and thus the Medicaid HMO enrollees would on average be just one-fourth as expensive. This is plausible given that the elderly and disabled, for whom per-recipient Medicaid spending is several times more expensive, typically remained in FFS.

Appendix Table 2 further demonstrations the negative relationship between provider payments and enrollment in managed care - in particular, enrollment in HMOs. Most notably, the negative relationship is strongest for hospital and physician payments. The relationship is weaker for prescription drugs, which is unsurprising because many managed care programs carve out prescription drugs to take advantage of statutory Medicaid pharmaceutical rebates. There is no relationship for long-term care providers, likely both because long term care is often carved out of managed care programs and because the aged and disabled are less likely to be enrolled in managed care. Thus, these specifications serve as a useful "falsification test" for our identification strategy. 
Taken together, the results in this subsection reveal that the policy-induced shift of Medicaid recipients from fee-for-service into Medicaid managed care has resulted in a shift of program expenditures from providers to insurers. Of course, many of these same providers ultimately receive the payments disbursed to health insurers. Interestingly, this shift in the composition of Medicaid spending is only present for Medicaid HMOs. Furthermore, and as expected, revenues for certain categories of providers, such as long-term care facilities, have been relatively unaffected by Medicaid managed care. The next subsection explores whether the mandate-induced shift from fee-for-service to MMC has affected total Medicaid spending.

\section{B. The Effect of Mandate-Induced MMC Enrollment on Total Medicaid Spending}

To investigate the effect of the mandate-induced increases in MMC enrollment on Medicaid spending, we begin by estimating specifications of the following type:

(6) $\log \left(\operatorname{McdSpend}_{\mathrm{kt}}\right)=\alpha_{5 \mathrm{t}}+\rho_{5 \mathrm{k}}+\mu_{5} * \log \left(\operatorname{McdRecips}_{\mathrm{kt}}\right)+\beta_{5} * \mathrm{MMC}_{\mathrm{kt}}+\delta_{5} * \mathrm{X}_{\mathrm{kt}}+\mathrm{t} * \rho_{5 \mathrm{k}}+\varepsilon_{5 \mathrm{kt}}$

In this regression, the outcome variable is the log of Medicaid spending in state $\mathrm{k}$ and in year $\mathrm{t}$. We control for the same explanatory variables described above $\mathrm{e}^{22}$ and also for the $\log$ of the number of Medicaid recipients. State fixed effects control for time invariant differences across states in the level of Medicaid spending, while state-specific linear time trends control for differences across states in the average growth rate of Medicaid spending.

Table 8 summarizes the results from this set of analyses. The first specification summarized in column (1) is a reduced form estimate of the fraction of Medicaid recipients residing in a county with an MMC mandate. The point estimate of -0.005 for $\beta_{5}$ is small in magnitude and is statistically insignificant with a standard error of 0.025. This suggests that the average effect of the MMC mandates on Medicaid expenditures was close to zero.

\footnotetext{
${ }^{22}$ One concern with this specification is that the mandates may affect the characteristics of Medicaid recipients, and thus controlling for age and the basis of eligibility could bias our estimate for the effect of MMC mandates. However, our estimate for this effect is almost identical if we do not control for these characteristics.
} 
The IV estimate for the spending effect of the fraction enrolled in MMC is summarized in the next column. As one would expect given the first-stage estimates described above, at -0.014 the magnitude of this IV estimate is higher than the reduced form estimate. However, it is also less precisely estimated with a standard error of 0.060 , and thus our 95 percent confidence interval includes effects ranging from approximately a 13 percent reduction in Medicaid spending to a 10 percent increase. We can therefore rule out large effects of MMC contracting on Medicaid spending in the average state, and thus our results provide little support for the hypothesis that the shift to Medicaid managed care substantially reduced the strain on the typical state budget. ${ }^{23}$

The next two columns summarize the analogous reduced form and IV estimates that differentiate between Medicaid HMO enrollment and other forms of Medicaid managed care. All of the estimates in these columns are statistically insignificant, though the signs are interesting. For example, the point estimates in the IV specification in column 4 suggest that PCCM may lead to a modest reduction in Medicaid spending while the opposite is true for Medicaid HMO enrollment. ${ }^{24}$ It is not implausible that PCCM could lower Medicaid spending, as primary care physicians may be able to help Medicaid recipients increase the efficiency of their care by, for example, encouraging adherence to pharmaceutical protocols and steering them to certain providers, despite not being at financial risk. However, it is important to emphasize that these estimated effects are only suggestive as neither coefficient is statistically significant.

The IV results are largely consistent with the OLS specifications from Table 5, particularly those that cover the same time period. These results provide little evidence that MMC reduced state spending on Medicaid, and they provide suggestive evidence that Medicaid HMOs increased Medicaid spending by more than PCCM plans.

\footnotetext{
${ }^{23}$ We performed additional specification checks by, for example, excluding long-term care expenditures from our spending measure given that few states contracted with MMC organizations to coordinate long-term care services. Our key estimates for the effect of MMC mandates on Medicaid spending are very similar.

${ }^{24}$ The corresponding point estimates if we include variables for the percent in PCCM and HMO separately (rather than an MMC main effect and the fraction in HMOs) are -0.060 and 0.048 , respectively.
} 


\section{Differential Effects by Relative Provider Reimbursement Rates}

As discussed above, one possible source of heterogeneity in the effect of MMC contracting is the generosity of Medicaid provider reimbursement relative to reimbursement by commercial insurers. If, for example, Medicaid pays providers much lower rates than private insurers, then it may simply not be possible for these insurers to lower Medicaid spending (even if they reduce utilization to some degree). If, on the other hand, Medicaid's reimbursement is close to that by private insurers, then there may be some scope to reduce Medicaid spending through reductions in utilization of care.

To test this hypothesis, we next augment these specifications by interacting the MMC mandate variable with an index for the generosity of a state's Medicaid reimbursement (MC_Index) relative to private insurers. This data was constructed using state Medicaid reimbursement rates in 1989, two years prior to the start of our study period, and represents the average ratio of Medicaid to commercial reimbursement for a newborn delivery, which is the most common type of inpatient admission among Medicaid recipients. ${ }^{25}$ The mean value of MC_Index is 0.56 , implying that Medicaid was 44 percent less generous than commercial reimbursement in the average state. This measure does not vary within a state over time in our analyses and we de-mean it in all specifications.

There is substantial heterogeneity across states with respect to this index of relative state Medicaid reimbursement, with the ninetieth percentile state at 0.88 and the tenth percentile state at just 0.36. Two states have a value of exactly 1.00, implying that Medicaid is as generous as commercial insurers there, and no states are above this level. Thus according to this measure,

\footnotetext{
${ }^{25}$ See Schwartz et al (1991) for a detailed description of this data. Our specifications assume that the index captures the relative generosity of reimbursement for all health care providers, though it uses just newborn deliveries to estimate this. However, research by Duggan (2000) suggests that newborns account for the majority of all Medicaidinsured hospital discharges, and this would likely be especially true for the MMC population. It is also worth noting that neither Arizona nor Wyoming were included in this survey. Also, this data is for just one year and is not updated over time. While national analyses of Medicaid reimbursement generosity have been conducted since this study appeared, virtually no studies aim to measure this on a state-by-state basis relative to commercial insurance. We therefore use this relatively old data, which was constructed just prior to the start of our study period.
} 
Medicaid was not more generous than commercial health insurance in any state around the beginning of our study period.

The results displayed in the fifth column of Table 8 strongly suggest that the generosity of a state's Medicaid reimbursement, relative to private insurers, is a significant determinant of the spending effects of MMC contracting. ${ }^{26}$ More specifically, the statistically significant estimate of 0.251 for the interaction between the mandate variable and MC_Index indicates that MMC lowered spending by significantly more in states with generous provider reimbursement. This suggests that, if Medicaid provider rates are particularly low, then Medicaid managed care is unlikely to reduce spending. The estimate of -0.251 suggests that changing the index by one standard deviation (0.19) is associated with a 4.8 percentage point change in the reduced-form effect of the mandate. Given that MC_Index is demeaned, the point estimate of -.012 for the main mandate variable suggests that the effect of MMC contracting for a state with average Medicaid reimbursement generosity is very small.

In the next specification, we investigate whether this effect is specific to HMOs by interacting the Medicaid reimbursement index with both the main mandate variable and the HMO mandate variable. Theoretically, one might expect the difference to be present only for HMOs, as state governments continue to directly reimburse health care providers under PCCM. On the other hand, a state with relatively generous Medicaid reimbursement may experience more overutilization under a fee-for-service system. Thus there may be more scope for primary care case managers to reduce utilization through better care coordination in such a state. It is therefore theoretically ambiguous whether the spending effect of generous Medicaid reimbursement would be restricted to HMOs or would also be present in states that used PCCM.

\footnotetext{
${ }^{26}$ To investigate whether states with higher Medicaid provider reimbursement rates were more (or less) likely to shift Medicaid recipients into MMC plans, we regressed the twelve-year change in the state-level MMC mandate on this index. The point estimate was negative (suggesting that states with more generous provider reimbursement were less likely to shift recipients into MMC) though statistically insignificant with a t-statistic of -1.22.
} 
The results summarized in the sixth column of Table 8 suggest that the effect of Medicaid provider reimbursement generosity is not significantly different for HMOs. More specifically, the estimate for the interaction between the MC_index and the HMO mandate variable is small in magnitude (0.039) and statistically insignificant, while the point estimate for the coefficient on the interaction of this index with the main mandate variable is unchanged and remains statistically significant. This suggests that states that employ either HMO or PCCM contracting can achieve cost savings if a state has relatively high provider reimbursement.

In the next specification, we introduce an alternative estimate of Medicaid reimbursement generosity, which is the ratio of it to Medicare reimbursement. ${ }^{27}$ This specification serves as a useful "falsification test" for whether the preceding estimates are actually picking up the effect of the relative reimbursement generosity of Medicaid versus private insurers. More specifically, the relationship between Medicaid and Medicare reimbursement rates has no bearing on whether HMOs can reduce Medicaid spending by taking advantage of low provider reimbursement rates in the private sector. The estimate for the interaction of this variable, which we label MM_Index, with the main mandate variable is small in magnitude and statistically insignificant. The next specification includes interactions with both MC_Index and MM_Index, and the coefficients on the interaction terms are consistent with the previous specifications. These findings suggest that the generosity of Medicaid reimbursement relative to commercial insurers is the key source of heterogeneity. This is as one would expect, as the relevant difference for the typical Medicaid managed care organization is Medicaid reimbursement versus private health insurance, not relative to Medicare.

Taken together, the results in this subsection suggest that, on average, MMC contracting did not lead to substantially lower (or higher) Medicaid spending during the 1991 through 2003 period. However, our findings do suggest that in states with relatively generous Medicaid reimbursement,

\footnotetext{
${ }^{27}$ Our primary source for this ratio is Norton and Zuckerman (2002) and these ratios are for 1998. However, the data are missing for several states in this survey, and thus we supplement it with data from Zuckerman et al (2009) for 2008. We scale down these later values to account for the increase in the average ratio from 1998 to 2008.
} 
contracting did achieve cost savings, while the opposite was true in states with less generous provider reimbursement. These findings underscore the importance of considering a state's unique circumstances when considering the potential savings from shifting Medicaid recipients from fee-forservice into managed care plans.

\section{Discussion}

From 1991 to 2009, the fraction of Medicaid recipients enrolled in HMOs and other managed care plans increased from 11 percent to 71 percent. These increases were largely driven by state and local mandates that required Medicaid recipients to enroll in a managed care plan. Using panel data for all 50 states and the District of Columbia over a thirteen-year period, the results in this paper suggest that shifting Medicaid recipients into managed care plans did not reduce Medicaid spending in the typical state. In fact, the OLS results for the extended 19-year period suggest that MMC increased Medicaid spending, particularly when states contracted out to HMO plans.

However, in states with relatively generous provider reimbursement rates, our results suggest that MMC contracting did reduce Medicaid spending below what it otherwise would have been. Our findings suggest that the opposite was true in states with low provider reimbursement rates at the start of our study period. The differential results for states with higher versus lower Medicaid provider rates relative to commercial rates did not distinguish between HMO and PCCM types of MMC. However, it is worth noting that residents of states with below-average FFS reimbursement rates (relative to commercial) are more than twice as likely to reside in a county with an HMO-only mandate (53.3 percent versus 24.7 percent). In conjunction with the final set of results, this observation may explain the OLS and IV findings that HMOs are more likely to increase state Medicaid expenditures.

To the extent that MMC may have increased state Medicaid expenditures on average, these increases may have been worthwhile in exchange for improved access to care or improved quality of 
care. However, the mixed results of the quality/access literature cited above suggests that additional spending did not provide states with improved health care for their Medicaid recipients.

The fraction of Medicaid recipients enrolled in MMC plans has increased only gradually during the last several years, growing from 71 percent in 2009 to 74 percent by $2011 .^{28}$ However, recent survey evidence suggests that a large number of states are planning to expand the reach of their MMC programs in the near future. This shift is likely to focus relatively more on elderly and disabled Medicaid recipients, who were largely exempted from the MMC mandates during the 1990s and early 2000s. While representing just one-fourth of Medicaid recipients, this group accounts for approximately two-thirds of Medicaid spending. Thus the share of Medicaid spending paid to managed care plans may increase by substantially more than the share of Medicaid recipients in MMC plans in the near future. Of course, because aged and disabled Medicaid recipients differ in many respects from most of the Medicaid recipients directly affected by previous MMC mandates, our findings would not necessarily translate to this group.

Projections from the Congressional Budget Office suggest that the Patient Protection and Affordable Care Act will increase the number of Medicaid recipients by approximately 9 million by 2015 (CBO 2012). This growth may be even larger if states currently expected not to proceed with their Medicaid expansion, such as Florida and Texas, do move forward with the expansion. It is plausible that the vast majority of those newly eligible for Medicaid, which will include individuals without health insurance with family incomes below 138 percent of the poverty line, will enroll in MMC plans. ${ }^{29}$

\footnotetext{
${ }^{28}$ As is apparent in Table 1, the slowdown in MMC enrollment generally and Medicaid HMO enrollment specifically started around 2000. This coincides with the timing of the beginning of a gradual decline in HMO enrollment among the privately insured (Cooper, Simon, and Vistnes, 2006).

${ }^{29}$ PPACA extended Medicaid to non-elderly U.S. residents with incomes at or below 133 percent of the federal poverty line (FPL). A provision of the subsequent Health Care and Education Reconciliation Act of 2010 effectively changed that to 138 percent of FPL.
} 
For all of these reasons, the reach of Medicaid managed care is likely to expand significantly in the years ahead. How states can achieve greater success in their MMC programs with respect to improved quality and lower Medicaid spending represents an important area for future research. For this it would be especially fruitful to obtain individual-level longitudinal data on MMC enrollment and Medicaid spending for a large number of states over a long time period, which would allow one to telescope in on specific geographic areas or on particular subpopulations within these states. Additionally, more research regarding the effect of Medicaid managed care on both the utilization and the price of health care services could shed light on the mechanisms through which MMC can affect program expenditures and the health outcomes of Medicaid recipients. 


\section{Reference List}

Aizer, A., Currie, J., and Moretti, E. "Does Managed Care Hurt Health? Evidence from Medicaid Mothers." The Review of Economics and Statistics 2007, 89(3), 385-399.

Baker, L. and Afendulis, C. "Medicaid Managed Care and Health Care for Children." Health Services Research 2005, 40(5), 1466-1488.

Basu, J., Friedman, B., and Burstin, H. "Managed Care and Preventable Hospitalization Among Medicaid Adults.” Health Services Research 2004, 39(3), 489-509.

Bertrand,M., Duflo, E., and Mullainathan, S. "How Much Should We Trust Difference-in-Difference Estimates?" Quarterly Journal of Economics 2004, 119(1), 249-275.

Bindman, A., Chattopadhyay, A., Osmond, D., Huen, W., and Bacchetti, P. "The Impact of Medicaid Managed Care on Hospitalizations for Ambulatory Care Sensitive Conditions." Health Services Research 2005, 40(1), 19-38.

Brown, J., Duggan, M., Kuziemko, I., and Woolston, W. "How Does Risk Selection Respond to Risk Adjustment? Evidence from the Medicare Advantage Program.” NBER Working Paper 16977, 2011.

Centers for Medicare and Medicaid Services. National Health Expenditure Projections 2009-2019. October 2010. Available at: http://www.cms.gov/Research-Statistics-Data-andSystems/Statistics-Trends-andReports/NationalHealthExpendData/Downloads/Proj2011PDF.pdf

Congressional Budget Office. Analysis of the Major Health Care Legislation Enacted in March 2010. Testimony by Douglas W. Elmendorf, Director, before the Subcommittee on Health Committee on Energy and Commerce of the U.S. House of Representatives 2011. Update available at: http://www.cbo.gov/sites/default/files/cbofiles/attachments/43472-07-24-2012CoverageEstimates.pdf

Cooper, P., Simon, K., and Vistnes, J. "A Closer Look at the Managed Care Backlash.” Medical Care 2006, 44(5), 4-11.

Coughlin, T., Long, S., and Graves, J. "Does Managed Care Improve Access to Care for Medicaid Beneficiaries with Disabilities? A National Study.” Inquiry 2008, 45(4), 395-407.

Currie, J. and Fahr, J. “Medicaid Managed Care: Effects on Children's Medicaid Coverage and Utilizatiton." Journal of Public Economics 2005, 89(1), 85-108.

Cutler, D., McClellan, M., and Newhouse, J. "How Does Managed Care Do It?” RAND Journal of Economics 2000, 31(3), 526-548. 
Dor, A., Grossman, M., and Koroukian, S. "Transaction Prices and Managed Care Discounting For Selected Medical Technologies: A Bargaining Approach.” NBER Working Paper 10377, 2004.

Duggan, M. "Hospital Ownership and Public Medical Spending." Quarterly Journal of Economics 2000, 115(4): 1343-1374.

Duggan, M. "Does Contracting Out Increase the Efficiency of Government Programs? Evidence from Medicaid HMOs.” Journal of Public Economics 2004, 88(12), 2549-2572.

Fisher, E., Wennberg, D., Stukel, T., Gottlieb, D., Lucas, F., and Pinder, E. "The Implications of Regional Variations in Medicare Spending, Part 2. Health Outcomes and Satisfaction with Care." Annals of Internal Medicine 2003, 138(4), 288-98.

Garrett, B. and Zuckerman, S. "National Estimates of the Effects of Mandatory Medicaid Managed Care Programs on Health Care Access and Use, 1997-1999." Medical Care 2005, 43(7), 649-657.

Glied, S., Sisk, J., Gorman, S., and Ganz, M. "Selection, Marketing, and Medicaid Managed Care." NBER Working Paper 6164, 1997.

Gottlieb D., Zhou, W., Song, Y., Gilman, K., Skinner, J., and Sutherland, J., "Prices Don't Drive Regional Medicare Spending Variations." Health Affairs 2010, 29(3), 1-7.

Greene, J., Blustein, J., Remler D. “The Impact of Medicaid Managed Care on Primary Care Physician Participation in Medicaid.” Medical Care 2005, 43(9), 911-920.

Gruber, J. Medicaid. In: Moffitt (Ed), Means-Tested Transfer Programs in the United States. University of Chicago Press; 2003.

Herring, B. and Adams, E. "Using HMOs to Serve the Medicaid Population: What are the Effects on Utilization and Does that Type of HMO Matter?" Health Economics 2011, 20, 446-460.

Howell, E., Dubay, L., Kenney, G., and Sommers, A. "The Impact of Medicaid Managed Care on Pregnant Women in Ohio: A Cohort Analysis.” Health Services Research 2004, 39(4), 825846.

Kaestner, R., Dubay, L., and Kenney, G. "Managed care and infant health: an evaluation of Medicaid in the US.” Social Science and Medicine 2005, 60(8), 1815-1833.

Kaiser Family Foundation. "Medicaid and Managed Care: Key Data, Trends, and Issues." Kaiser Commission on Medicaid and the Uninsured Policy Brief, 2010a.

Kaiser Family Foundation. "Medicaid: A Primer." Kaiser Commission on Medicaid and the Uninsured Report, 2010b. 
Kaiser Family Foundation. "Hoping for Economic Recovery, Preparing for Health Reform: A Look at Medicaid Spending, Coverage, and Policy Trends." Kaiser Commission on Medicaid and the Uninsured Report, 2010c.

The Lewin Group. "Medicaid Managed Care Cost Savings - A Synthesis of 24 Studies." Prepared for America's Health Insurance Plans, 2009.

Manning, W., Newhouse, J., Duan, N., Keeler, E., Leibowitz, A., and S. Marquis. "Health Insurance and the Demand for Medical Care: Evidence from a Randomized Experiment." American Economic Review 1987, 77(3), 251-277.

Miller, R. and Luft, H. "Does Managed Care Lead to Better or Worse Quality of Care? Health Affairs $1997,16,7-25$.

Norton, S. and Zuckerman, S. "Trends in Medicaid Physician Fees, 1993-1998." Health Affairs 2000, 19(4), 222-232.

Rawlings-Sekunda, J., Curtis, D., and Kaye, N. "Emerging Practices in Medicaid Primary Care Case Management Programs." Prepared for the U.S. Department of Health and Human Services, Office of the Assistant Secretary for Planning and Evaluation, 2001.

Schwartz, A., Colby, D., and Reisinger, A. "Variation in Medicaid Physician Fees." Health Affairs 1991, 10(1), 131-139.

Shen, Y. and Melnick, G. "Is Managed Care Still an Effective Cost Containment Device?" Forum for Health Economics \& Policy (Frontiers in Health Policy Research) 2006, 9(1), Article 3.

Sparer, M. "Medicaid Managed Care: Costs, Access, and Quality of Care." Robert Wood Johnson Foundation Synthesis Project 2012, Research Synthesis Report No. 23.

Zuckerman, S., Williams, A., and Stockley, K. "Trends in Medicaid Physician Fees, 2003-2008." Health Affairs 2009, 28(3), w510-w519. 


\section{Data Appendix}

This study utilized data on Medicaid expenditures, enrollment in Medicaid and in Medicaid managed care programs, and Medicaid demographic information from the Centers for Medicare and Medicaid Services (CMS) and mandate data from the Urban Institute.

\section{Expenditure Data}

Medicaid expenditure data comes from the CMS-64 Reports (available here for 1997-2009: https://www.cms.gov/MedicaidBudgetExpendSystem/02_CMS64.asp), which contain state-level expenditures for relatively narrow service categories for each year. These service categories were aggregated into broader categories as follows:

Hospital spending: inpatient and outpatient hospital spending, including disproportionate share payments

Physician: physician services, clinic services, labs and radiology, and other practitioners

Long-term care: hospice, intermediate care facilities, and nursing care facilities

Prescription drugs: prescription drug payments, net of manufacturer rebates

Home Health: home and community based services and home health services

Other providers: all other provider services, such as federally-qualified health centers and family planning services - excluding dental services or emergency services for undocumented immigrants

Managed care: payments to physicians for primary care case management programs; capitated payments to managed care organizations, prepaid health plans, all-inclusive elderly plans; and other Medicaid health insurance payments

Other expenditures: all other services such as administrative costs and premium and coinsurance payments on behalf of enrollees who are dually eligible for Medicare and Medicaid

Total expenditures include the sum total of all Medicaid expenditures, with the exception of dental expenditures and emergency services for undocumented immigrants; SCHIP expenditures are included in all of the above categories as applicable once the program began in 1998.

\section{Medicaid Enrollment and Demographic Data}

Both overall Medicaid and Medicaid managed care enrollment data as of June 30 come from the Medicaid Managed Care Enrollment Reports for the years 1991-2009 (The 2009 report is available here: http://www.cms.gov/medicaiddatasourcesgeninfo/04_mdmancrenrllrep.asp). Overall MMC enrollment comes from the unduplicated total managed care enrollment figure. Before 1996, the unduplicated total was not reported, so it was constructed from summed enrollment in individual 
managed care plans, excluding prepaid health plans for carved out services such as diabetes, substance abuse, and mental health because these often enroll individuals who are also enrolled in comprehensive medical plans. Dental managed care plans are excluded because these are inherently different from those offering medical services.

Before 1996, the MMC Enrollment Reports did not report June 30 Medicaid enrollment. In order to construct MMC penetration rates with a consistent base for each state, we estimated June 30 Medicaid enrollment for 1991-1995 using fiscal year Medicaid enrollment and the state-specific ratio between June 30 enrollment and fiscal year enrollment for 1996. Fiscal year Medicaid enrollment came from Medicaid Statistical Information Statistics reports (described here: http://www.cms.gov/msis/). For the handful of cases where constructed unduplicated managed care enrollment exceeded constructed Medicaid enrollment, the percent of Medicaid beneficiaries enrolled in managed care was capped at 100 percent.

Medicaid demographic information on age and eligibility through blindness or disability status also came from the MSIS data reports. In the early-1990s, these reports were filled out \& entered into CMS systems by hand, and in a two cases there were clear instances of data entry being swapped between columns. These instances are the following:

- Arkansas: age 85+ and age unknown were swapped for 1991 and 1992

- Connecticut: Eligibility through Blind/Disabled, Adults in FDC, and Title XIX were swapped in 1991

\section{Mandatory Managed Care Enrollment Policies}

The Urban Institute conducted surveys in 1998 and 2001 to determine what types of MMC policies existed for the welfare population in different geographic areas and years. Their surveys differentiated between primary care case management programs and comprehensive managed care organization programs and between voluntary and mandatory programs of both types. Survey data was cross-checked with other sources, such as the CMS MMC enrollment reports and case studies where possible. The resulting data set reports the existence of these managed care policies using binary variables for each county-year observation. The 1998 survey is described further in Garrett, et al 2003, which uses survey data from 1991-1995 in conjunction with National Health Interview Survey data from the same time period to study the effect of MMC mandates on access and utilization.

State-level mandate variables were constructed by combining these indicator variables with countylevel population data. For example, if a state had two counties - one with 70 people and a mandatory managed care policy, and the other with 30 people and no managed care policy - the state-level variable, percent mandatory, would equal 70 percent because 70 percent of the state's population lives in a county with a mandatory managed care policy.

In order to capture additional years of data beyond the MMC expansions in the 1990s, the Medicaid mandate variables were extended to 2003. There were few changes in MMC mandates between 1999 
and 2001, and the plan-level MMC enrollment report tables for 2002 and 2003 were used to identify which states expanded or contracted the geographic reach of their MMC policies. For example, Kentucky's mandatory PCCM program began operating statewide in 2002 and Mississippi dropped its mandatory PCCM program in 2002. Our empirical results are very similar if we restrict attention to the 1991 to 2001 period.

\section{Reference List}

Garrett, B., Davidoff, A., and Yemane, A. "Effects of Medicaid Managed Care Programs on Health Services Access and Use." Health Services Research 2003, 38(2), 575-594. 